\title{
Los oratorianos de San Felipe Neri y los inicios de la arquelogía cristiana.
}

\author{
Mónica Montoro Castillo \\ Universidad Autónoma de Madrid
}

\section{Resumen}

Con la aparición del Protestantismo en Europa se hace urgente la reforma de la Iglesia Católica. Las ciencias históricas se ponen entonces al servicio de la Reforma, entre ellas la arqueología que pretendía demostrar la antigüedad del Cristianismo. Es en este contexto en el que el Oratorio de San Felipe Neri jugará su papel protagonista. Maestro y asesor de algunas de las grandes figuras del momento Neri influirá de manera decisiva en el nacimiento de la Arqueología Cristiana en Roma.

En este proceso participarán también importantes personalidades españolas, algunas asiduas a las reuniones del Oratorio en Roma, lo que permitirá un desarrollo paralelo de la nueva disciplina en ambos países. Entre los nombres más famosos encontramos a Alonso de Chacón, autor junto con De Winghe y Macarios de la documentación que permitirá a Bosio escribir su famosa Roma Sotterranea.

\section{Abstract}

With the appearance of Protestantism in Europe, the reform of the Catholic Church becomes urgent. Historical sciences are then put at the service of the Reformation, among these, archaeology that tried to demonstrate the antiquity of Christianity. It will be in this context in which the Oratorio of San Felipe Neri will play its protagonist role. Teacher and adviser of some of the great figures of the moment, Neri will have a decisive influence on the birth of Christian Archeology in Rome.

In this process, important Spanish personalities, some regulars to the meetings of the Oratorio in Rome, will also participate, which will allow a parallel development of the new discipline in both countries. Among the most famous names we find Alonso de Chacón, whom in cooperation with De Winghe and Macarios will prepare the documents that will allow Bosio to write its famous Roma Sotterranea.

Palabras clave:

Arqueología Cristiana. San Felipe Neri. Humanismo. Reforma Católica. Catacumbas. Roma

\section{INTRODUCCIÓN}

Considerado como el padre de la arqueología cristiana, Antonio Bosio fue el primero en llevar a cabo una investigación sistemática de las catacumbas. Sin embargo, su trabajo no habría sido posible sin la labor previa de toda una serie de personas que abonaron el camino para la explo- ración arqueológica. En este proceso jugará un papel fundamental el grupo de San Felipe Neri, cuya labor tendrá como principal objetivo recoger pruebas que justifiquen la doctrina católica y que la defiendan de los ataques de las nuevas iglesias reformadas. En este contexto, haremos especial incidencia en todos aquellos españoles 
que con su trabajo, tanto dentro como fuera de Roma, participaron en este proceso del nacimiento de la arqueología cristiana y cuya relevancia ha sido minimizada, cuando no totalmente eclipsada, por la historiografía posterior.

En realidad, el ambiente en el que debía surgir la arqueología llevaba años fraguándose en la mejor de las circunstancias: en torno a los círculos de poder. El amor por las antigüedades que mostraban los seguidores de los studia humanitatis convirtió a la alta sociedad en mecenas y rastreadores de todo tipo de vestigios, que se convertirán en base de importantes colecciones. Este interés por los restos del pasado desarrollado durante el Renacimiento alcanzó rápidamente a Papas y Reyes que se mostraron especialmente interesados por otro tipo de restos: las reliquias sagradas. De este modo, "a finales del siglo XV la arqueología era ya una auténtica moda en Italia" (Gómez Moreno 1994: 256). En medio de este proceso cultural se produce el Concilio de Trento. Cuando en 1545 se inicia el Concilio, la Reforma de la Iglesia Católica hacía tiempo que se venía forjando. Desde finales del siglo XV, este movimiento se había hecho perceptible en algunos países, especialmente en España, primero con los Reyes Católicos y posteriormente con Carlos V, quien, hasta el último momento, intentará mantener la unidad de la Iglesia. Es ahora cuando ese interés renacentista por las antigüedades se pone al servicio de la defensa del catolicismo generando una combinación perfecta para el desarrollo de la arqueología. De este modo, y por necesidades fundamentalmente políticas, la arqueología, que durante los siglos precedentes había protagonizado gran parte de las selectas reuniones culturales italianas, es ahora orientada en una dirección muy concreta: la arqueología cristiana. Lo cierto es que el salto de la arqueología clásica de corte humanista a la arqueología cristiana no fue especialmente traumático y en él jugarán un papel fundamental los Mirabilia, donde, ya desde el siglo XII se asociaba la figura de Cristo con la de Augusto como paradigma de buen gobernante en el momento del nacimiento de Jesús. No obstante, el salto más grande, aquel que permitirá un estudio de las ruinas de la ciudad de Roma desde un punto de vista puramente histórico, aún tendrá que esperar.

\section{El Oratorio de San Felipe Neri}

Los métodos utilizados por la Reforma para la victoria del catolicismo fueron variados. Ya antes del inicio del Concilio de Trento, se opta por la vuelta a una política represiva mediante la restauración del Santo Oficio (1542) y la creación de la Congregación del Índice (1543), con el fin de determinar y prohibir todos aquellos escritos considerados heterodoxos. Junto a estas medidas defensivas otras actuaciones estuvieron encaminadas al refuerzo del aspecto puramente reformista. Paulo III llevó a cabo una verdadera renovación de la Curia romana mediante el nombramiento de nuevos cardenales dignos de la obra que les iba a ser encomendada, y presididos por el cardenal Contarini, auténtico núcleo de la Reforma Católica en Roma. Las órdenes religiosas fueron el segundo punto de renovación. Su importancia en la regeneración católica se convirtió en algo fundamental para la Iglesia: habían conseguido la preponderancia en el ámbito teológico, en la predicación y en la cura de almas urbanas, por no hablar de la educación de la aristocracia. En algunos casos la reforma de las familias vino motivada y dirigida por la política regia tal y como sucedió en la España de los Reyes Católicos, pero junto a esta "reforma institucional" aparece todo un movimiento de eremitorios y oratorios que representan un reforma espontánea de hombres y grupos que optan por una forma de vida más pura, más cercana a la de las primeras comunidades cristianas. En este sentido, pocos movimientos ejercieron una acción tan profunda como la de los oratorianos de San Felipe y los jesuitas, pues ambos grupos se convertirán en los principales representantes de la lucha contra las iglesias reformadas.

De carácter fuertemente monárquico y aristocrático, el papel de la compañía de Jesús en la reforma de la Iglesia es, en general, bien conocido. Muchos jesuitas fueron enviados a participar en las reuniones de Trento, especialmente en la tercera, donde adquirieron un relevante protagonismo. Al igual que los otros grandes místicos contrarreformistas de la época: Santa Teresa de Jesús o San Juan de la Cruz, San Ignacio de Loyola supo combinar la teoría y la práctica en la comprensión de los misterios de la Fe, dejando atrás los complejos procesos de los místicos medievales y acercando las abstractas discusiones teológicas a los fieles. 
Menos conocidos son los Oratorianos de San Felipe Neri. Su actuación se orientó a la regeneración de la ciudad de Roma y sin duda fue una de las que más transformaron la capital del catolicismo. Elegida como destino misional, en 1548 San Felipe funda en Roma la Cofradía de la Santísima Trinidad, popularmente conocida como la Cofradía de los pobres, creada para asistir a los indigentes, los peregrinos y los presos. Fue por aquel entonces, en torno a la Iglesia de San Girolamo, donde surgieron los primeros coloquios y visitas a las basílicas de Roma. Con el tiempo, la afluencia a estas reuniones piadosas fue tan amplia que en 1575, y con la sanción del Papa Gregorio XIII, se funda el Oratorio. Este movimiento nunca se convirtió en una orden centralizada. Se trataba más bien de una congregación de sacerdotes seculares unidos por la obediencia voluntaria y la caridad sin ningún tipo de voto religioso. Su organización pretendía seguir el modelo de los grupos de cristianos primitivos mostrando, desde su origen, la ideología del fundador. El mismo año de su fundación el Oratorio traslada su sede a la iglesia de Santa María in Vallicella. El número de asistentes sigue aumentando y en poco tiempo el Oratorio se convierte en un destino de moda, tanto para los extranjeros que llegaban a Roma como consecuencia de las reuniones de Trento, como para lo más granado de la sociedad de la urbe. Cardenales, obispos e incluso papas se hacen asiduos a las reuniones del Oratorio y a los paseos-peregrinajes que San Felipe organiza a las siete Basílicas de la Ciudad Santa.

Uno de los mayores aciertos de San Felipe en el desarrollo cultural y social de su grupo fue, sin duda, la elección de sus alumnos. Entre ellos encontramos figuras tan relevantes como la de Francesco María Tarugi. Caballero de capa y espada y primo de Julio III, Tarugi estaba emparentado con los principales papas y obispos de la época y fue una excelente base de apoyo para el trabajo de Felipe. Como Neri, Tarugi organizaba prestigiosas reuniones culturales en las que se desarrollaba el pensamiento humanístico. Otro de sus alumnos más famosos fue San Carlos Borromeo, sobrino del Cardenal Médicis (futuro Pío IV) y miembro de una de las más relevantes familias italianas. San Carlos llegó a ser uno de los obispos contrarreformistas más influyentes de la época. En Trento ocupó el cargo de secre- tario general y tras la muerte de Pío IV fue nombrado arzobispo de Milán, ciudad donde funda una nueva congregación a disposición de la Reforma Católica: los Oblatos de San Ambrosio. Carlos Borromeo fue un firme defensor de las órdenes del Oratorio y de la Compañía de Jesús, en los que se apoyó para llevar a cabo sus reformas en Milán. Borromeo fue sin duda el mayor promotor de la Contrarreforma en la Corte papal y modelo de enérgica aplicación de las disposiciones tridentinas en Milán. Mientras que miembros como éstos aportaban al grupo de San Felipe el prestigio y la influencia política, otros construían el contenido intelectual del Oratorio. Entre estos cabe destacar la figura de César Baronio. A diferencia de los dos anteriores, Baronio procedía de una familia modesta, que tuvo que dedicar enormes esfuerzos para que su hijo pudiera estudiar derecho en Nápoles. Convertido en sacerdote por influencia de San Felipe, éste le encargó la tarea de escribir una gran historia de la Iglesia como réplica a las Centurias de Magdeburgo. Esta obra había sido escrita por los protestantes bajo la dirección de Flacio Ilírico con el objetivo de mostrar la corrupción que Roma había introducido en el evangelio puro, en la Iglesia original. Estos Anales eclesiásticos de Baronio alcanzaron pronto una gran fama, siendo apoyado su trabajo por eminentes personalidades, entre ellas el propio Sixto V, quien se dice favoreció al historiador con una paga fija por su trabajo de preparar los Anales. Baronio llegará a ser cardenal y su obra conocida y continuada mucho tiempo después de su muerte.

\section{LAS CIENCIAS HISTÓRICAS AL SERVICIO DE LA REFORMA CATÓLICA}

La acusación por parte de los protestantes de que la Iglesia Católica se separaba cada vez más del espíritu de la Iglesia primitiva, y la publicación de las famosas Centurias de Magdeburgo, supuso un importante estímulo para los autores católicos. Era necesario estudiar la antigüedad del cristianismo y aportar pruebas fehacientes para justificar los dogmas y principios católicos vigentes: la antigüedad de la misa, la interpretación de las Sagradas Escrituras, el sacerdocio ministerial o el culto a los Santos entre otras 
prácticas cuya autenticidad negaban las nuevas iglesias reformadas. Es precisamente aquí donde la arqueología se convierte en un instrumento fundamental en la lucha por la Reforma Católica.

Los primeros trabajos sobre ciencias históricas proceden del humanismo y más concretamente del estudio de los Santos Padres, una de cuyas ediciones hacía tiempo que había sido publicada por Erasmo. En Trento fueron utilizados como material probatorio manuscritos vaticanos de los padres griegos aportados por Guglielmo Sirleto al que se puede considerar como el precursor de la patrística griega. También Marguerin de la Bigne publicó su Biblioteca Sanctorum Patrum como refutación a las Centurias. Pero habrá que esperar hasta finales del siglo XVI para encontrar a las grandes figuras de la historiografía eclesiástica. Onofre Panvinio es una de ellas. Sus obras fundamentales, un Cronicón de la Iglesia y el Epítome de los Romanos Pontífices, le han granjeado el título de "Padre de toda la historia", si bien, el mayor mérito de este agustino, del que hablaremos más adelante, es el de haber sido el verdadero iniciador de los estudios de arqueología cristiana.

Si alguna figura destaca en el contexto de las ciencias históricas este es, sin duda, Cesar Baronio. Sus Anales eclesiásticos, escritos, como ya se dijo, en respuesta a las Centurias de Magdeburgo, se convirtieron en la referencia de la lucha de la ciencia católica contra el protestantismo. Baronio dedicó todos sus esfuerzos a esta monumental obra de la que llegó a publicar doce volúmenes entre 1588 y 1607 . No pudo acabar su labor que quedó interrumpida en el siglo XII, pero la importancia de esta obra ha sido tal que muchos otros han continuado su trabajo con sucesivas ampliaciones y síntesis de los Anales. La más importante de ellas fue la del oratoriano Raynaldus con nueve volúmenes que comprenden desde donde la dejó Baronio hasta 1566.

En este contexto, la arqueología se convertiría en una herramienta clave para rechazar la acusación de los protestantes de que la Iglesia Católica se había desviado de la Iglesia primitiva. Como ya hemos dicho, el iniciador de los estudios arqueológicos en Roma fue Onofre Panvinio con dos obras esenciales: Sobre las más venerables basílicas de la ciudad de Roma, y Sobre el rito de sepultar a sus difuntos entre los antiguos y de sus cementerios. Como tendremos ocasión de observar, estas obras están marcando el campo de acción de lo que podríamos considerar los primeros trabajos de campo en el ámbito de la arqueología cristiana.

Tradicionalmente se ha considerado el 31 de mayo de 1578 como el detonante de estos trabajos. Ese día, mientras los campesinos trabajaban el suelo de la Viña Sánchez, situada en la Vía Salaria, ésta se vino abajo, dejando al descubierto las catacumbas de los Jordanos. Si bien el propio derrumbamiento imposibilitó el estudio de las galerías que quedaron nuevamente sepultadas, este acontecimiento supuso el nacimiento de un interés renovado por estos antiguos cementerios. En realidad las catacumbas siempre habían despertado un fuerte atractivo para todos aquellos cristianos que visitaban Roma. Durante el Renacimiento, las catacumbas se usaron como lugares de meditación y de veneración a los Santos y Mártires allí enterrados. De hecho, es conocido que San Felipe Neri era asiduo a las catacumbas de San Sebastián, donde, según las noticias de su vida, pasaba muchas noches buscando modos de promover la Reforma Católica. Una de las experiencias místicas más famosas de las vividas por el Santo tiene lugar en estas catacumbas el día de Pentecostés de 1554, cuando un globo de fuego penetraría en su corazón dilatándoselo.

Ya desde el siglo VIII se venían recopilando guías de las grutas destinadas a todos aquellos que quisieran venerar un tumba en concreto. Son los llamados itinerarios. Uno de los más conocidos es el de William de Malmesbury escrito en el siglo XII y destinado probablemente a los cruzados que acudían en peregrinación a Roma. Los itinerarios se convirtieron en una herramienta fundamental para la investigación arqueológica, del mismo modo que llevaban tiempo siéndolo para los traficantes de reliquias sagradas.

Además de las catacumbas, las iglesias también se convirtieron en focos de interés arqueológico. Una de las actividades realizadas por el Oratorio era la visita-peregrinación a las siete principales basílicas de Roma, que tenían lugar todos los años en las fechas del Carnaval. Estos paseos se verán beneficiados por la política urbanizadora de Sixto V quien abrió numerosas calles y vías conducentes a Santa María 
Maggiore con la intención de unir todas las basílicas de Roma con esta primera ${ }^{1}$. Una de las informaciones más interesantes a este respecto la encontramos en un episodio de la vida de San Felipe Neri. En 1575 el Oratorio traslada su sede a la iglesia de Santa María in Vallicella, pero enseguida se ve que esta iglesia no reúne las condiciones necesarias para albergar a todos los seguidores del Santo. Una noche, San Felipe es avisado por la Virgen de que la iglesia está a punto de derrumbarse. El Santo decide entonces demoler el edificio y construir uno más grande en su lugar. La noticia en cuestión concluye diciendo que bajo su dirección la excavación comenzó en el lugar donde una antigua fundación yacía escondida ${ }^{2}$. Al margen del halo de sacralidad y misticismo con el que se rodea la historia, lo que si parece poder entresacarse es el interés por encontrar la construcción cristiana precedente enterrada bajo Santa María in Vallicella. Ya por entonces era conocido que la zona donde se asentaba la Chiesa Nuova era el antiguo Tarentum de época romana. Desde este lugar, rico en estaño sulfuroso, se suponía que se accedía a los infiernos, razón por la cual los romanos erigieron altares a Proserpina. En época medieval, esta zona, situada en el camino de los peregrinos que se dirigían a Roma, alcanzó un importante desarrollo. En ella se ubicaban varias iglesias entre las que se encontraba la primitiva Santa María in Vallicella cuya fundación se atribuía al Papa San Gregorio Magno en el siglo VI. En la iglesia se conservaba una antigua imagen de la Virgen, considerada milagrosa y que hoy en día se encuentra en el retablo del altar mayor de la Chiesa Nuova, detrás del lienzo de Rubens, al que se le dotó con un mecanismo que permite deslizar el cuadro para descubrir el icono.

1 No obstante Sixto V no sólo fue uno de los grandes urbanizadores de la Ciudad, sino también uno de los mayores destructores de obras arqueológicas de su tiempo. Hasta tal punto llegó la situación que un grupo de nobles romanos reclamarán el fin de este destrozo, a lo que Sixto V contestará que "entre las antigüedades quería acabar con las odiosas, pero que el resto si lo necesitaba, lo restauraría" (Von Ranke 1981: 219)

2 Noticia extraída de la Vida de San Felipe Neri redactada por la congregación de los Sagrados Corazones Atravesados de Jesús y María.

3 Precisamente este Papa es uno de los más relacionados con
Algún tiempo después, encontramos una historia parecida protagonizada por Clemente $\mathrm{VIII}^{3}$. Desde 1452 llevaban realizándose trabajos de reconstrucción de la Basílica original constantiniana de San Pedro. Aprovechando estas obras, el Papa planeó excavar debajo del nuevo altar mayor, lugar donde los obreros aseguraban haber visto la cruz que debía señalar la tumba de San Pedro. Las excavaciones nunca se llevaron a cabo, pero en 1940 el hallazgo de parte de un cementerio debajo de la citada iglesia daba la razón a las frustradas esperanzas de Clemente VIII.

Desde mi punto de vista, ninguno de estos acontecimientos es fruto de la casualidad. Debajo de todos estos relatos con claros componentes fabulosos, existe un interés arqueológico por parte de los protagonistas, sustentado en un conocimiento previo sobre lo que estos lugares escondían.

\section{EL PAPEL DE LOS ESPAÑOLES}

La arqueología cristiana surgió en el lugar y en el momento preciso como consecuencia del devenir histórico de la ciudad Santa por excelencia. En el desarrollo de este proceso, intervinieron importantes personalidades españolas cuyo protagonismo es incuestionable y cuyo trabajo no siempre ha sido valorado en su justa medida.

Las intensas relaciones políticas y culturales de nuestro país con los territorios italianos se retrotraen al siglo XIV, no obstante, será en el siglo siguiente, con la elección del valenciano Alfonso de Borja como nuevo Papa (Calixto III) en el cónclave de 1455 y la de su sobrino, Rodrigo de Borja, quién le sucederá con el nom-

el Oratorio: fue hijo de confesión de Baronio, eligió a San Felipe como consejero en relevantes cuestiones políticas y bajo su pontificado varios miembros del grupo del Santo fueron ascendidos en sus cargos religiosos. Esta estrecha relación de Clemente VIII con el Oratorio es recogida por Ranke en su obra sobre la historia de los Papas: "Después de haber trabajado durante toda la semana, su descanso consistía en hacer venir a los padres de Vallicella para conversar con ellos sobre profundas cuestiones de religión. La fama de hombre virtuoso, piadoso, de vida ejemplar que siempre disfrutó aumentó de manera extraordinaria con este estilo de vida” (Von Ranke, 1981: 338) 
bre de Alejandro VI, cuando el protagonismo español se haga especialmente patente. Bajo la influencia de estos Papas, la presencia de españoles en la Curia y en Italia en general aumenta de manera considerable, poniéndose las bases de lo que algunos autores han llamado "la Roma Española”. Por supuesto, los grandes concilios del siglo XV motivarán la llegada a Roma de algunas de las principales personalidades españolas de momento, la mayoría eclesiásticos, pero también hombres de letras con un marcado interés cultural. Durante el reinado de los Reyes Católicos, los contactos culturales con la Italia Renacentista fueron muy favorecidos y el intercambio de viajeros de ambas nacionalidades se convirtió en algo habitual. Ya en el siglo XVI, (al menos hasta el reinado de Felipe II) Italia y especialmente Roma, se convertirá en un destino obligatorio para todos aquellos estudiosos españoles que deseen completar su formación humanística.

Tal y como dice Ángel Gómez Moreno “...para encontrar españoles con una formación arqueológica de cierto relieve, hemos de avanzar [...] hasta llegar al célebre encuentro de Mantua convocado por Pío II (entre 1459-1461) donde acudieron Rodrigo Sánchez de Arévalo, obispo de Palencia y representante de la Curia, Joan Margarit, embajador de Juan II de Aragón y Alfonso de Palencia, que acompañaba al Conde de Tendilla" (Gómez Moreno 1994: 269). Precisamente uno de ellos se convertirá en el primer nombre español asociado al nacimiento de la arqueología cristiana en Roma. Rodrigo Sánchez de Arévalo nace en Santa María de Nieva (Segovia) en 1404, estudiará derecho en Salamanca y más tarde se hará bachiller en Teología y Artes. Asiste al Concilio de Basilea junto con Alfonso de Cartagena, obispo de Burgos, donde desempeñará cargos de relativa importancia. En 1455 viaja a Roma para presentar sus respetos al nuevo Papa, el español Calixto III, el cual le hará cargo de los asuntos de España. Tras ser nombrado obispo de Oviedo vuelve a España, pero en 1460 regresa a Roma donde residirá hasta su muerte. Durante el tiempo que pasa en Roma, Sánchez de Arévalo trabaja como defensor del papado frente a los conciliaristas, y desempeña el cargo de guardián del castillo de Sant'Angelo, lugar donde, además de ubicarse el famoso presidio, se custodiaban los tesoros pontificios. Este cargo le permitirá entrar en contacto con numerosos humanistas allí presos, lo que desarrolló aún más sus aficiones artísticas, entre las que se encontraba el gusto por la arqueología, tal y como manifiestan algunos de sus escritos como el titulado Cremonensium monumenta Romae existentia. La evidente inclinación que Sánchez de Arévalo mostraba por la arqueología pudo ir más allá de un mero interés humanístico. Ya vimos como uno de los acontecimientos cruciales en el nacimiento de la arqueología cristiana tiene lugar en el año 1578 cuando bajo el suelo de la Viña Sánchez aparecen las Catacumbas de los Jordanos. Cómo puede suponerse, el nombre de Sánchez no era muy corriente en la Italia de la época, no es muy difícil suponer que esta famosa viña formaría parte de las propiedades de nuestro Sánchez de Arévalo. Por otra parte, teniendo en cuenta sus aficiones, lo más probable es que la adquisición de este terreno por parte del obispo español no tuviera como única finalidad la explotación de las Viñas. El que esta finca estuviera situada entre las Catacumbas de Priscila y Santa Felicitas y teniendo en cuenta la información de los itinerarios, no es difícil pensar que una persona con inquietudes arqueológicas como Sánchez de Arévalo adquiriera ese terreno con la pretensión de encontrar un nuevo cementerio cristiano primitivo bajo el mismo. Acontecimiento que tendrá lugar un siglo más tarde.

En España, el testigo de la arqueología cristiana será recogido por Ambrosio de Morales quién creará en torno suyo, un estrecho grupo de colaboradores entre los que cabe destacar personalidades muy relacionadas con el mundo de la arqueología como la de Fray Alonso de Chacón (el famoso Ciaconius), Benito Arias Montano, Juan Fernández Franco o Alvar Gómez entre otros. Este grupo de humanistas españoles centrará su atención en los restos del pasado Imperial, atendiendo al estudio de los vestigios de las antiguas ciudades romanas, las monedas y medallas, en el marco del coleccionismo. Expresión de este trabajo es su obra más célebre: Las Crónicas de España, iniciadas por Florián de Ocampo (libros I-V) y que Morales continuara a partir del año 209 a.C.(libros VI al XVII, publicados entre 1574 y 1586). Con el objetivo de llevar a cabo este trabajo, Ambrosio de 
Morales realizará numerosos viajes recopilando todo tipo de documentación histórica y estudiando los vestigios arqueológicos de aquellos lugares que visitaba. En el desarrollo de estos estudios, Ambrosio de Morales recopilará una gran cantidad de objetos arqueológicos que pasarán a formar parte de su famosa colección privada. De este modo, Morales consiguió difundir entre sus alumnos un nuevo método de reconstrucción histórica basada en la recopilación, estudio y análisis de las fuentes, tanto documentales, como arqueológicas. Influenciado por los trabajos que en estas fechas se estaban realizando en Roma y con el trasfondo del proceso de Contrarreforma en el que España participa muy activamente, la segunda mitad de siglo estará marcada, también en la Península Ibérica, por la preeminencia de la arqueología cristiana.

Durante todo el siglo XVI, los viajes de ida y vuelta de los humanistas españoles determinarán el desarrollo de la recién estrenada disciplina arqueológica. Uno de estos eruditos será Benito Arias Montano, participante en las últimas sesiones de Concilio de Trento. Muy comprometido con la causa contrarreformista, es conocido también por su afición al mundo clásico, que le llevó a conformar una famosa colección en la que se incluían piezas arqueológicas.

Más interesante aún es la figura de Antonio Agustín. Arzobispo de Tarragona, se formó en Roma como protonotario apostólico bajo la protección del embajador Diego Hurtado de Mendoza ${ }^{4}$. Cómo este último, se aficionó al coleccionismo y, especialmente a los estudios numismáticos y epigráficos, de los que se dice organizó su estudio de manera científica en España. Antonio Agustín es autor de los Diálogos de las monedas, inscripciones y otras antigüedades, publicada de manera póstuma en Tarragona en 1587 y casi inmediatamente traducida y difundida por toda Europa, donde alcanzará una gran trascendencia, convirtiéndose en obra de obligada referencia al menos hasta el siglo XVIII. En todo este conocimiento jugará un papel decisivo sus años de formación en Italia, donde entrará en contacto con el amplio

4 Diego Hurtado de Mendoza, participó en Trento como embajador oficial en representación de Carlos V. Este ilustre aristócrata fue también un reputado humanista y como tal círculo de coleccionistas y eruditos romanos, así como con miembros destacados del círculo de San Felipe Neri tal y como se deriva de su conocida amistad con Onofre Panvinio y su estrecha relación con Gregorio XIII (Carbonell 2000: 121-138).

Pero si algún español llega a alcanzar verdadera fama como arqueólogo en Roma, ese es Alonso Chacón, más como Ciacconio. Nacido en Jaén en 1530, se licenció en Filosofía y Teología. En 1566 Pío V le llama a Roma para encargarle la dirección de la biblioteca Vaticana, y posteriormente será nombrado penintenciario en Santa María la Mayor por Gregorio XIII. Durante las últimas décadas del siglo y acompañado por los otros dos protagonistas de la arqueología de la época: Philip de Winghe y Juan L'Heureux (también conocido como Macarios) analizará parte de las catacumbas que se habían ido redescubriendo durante los últimos tiempos, copiando los frescos que en ellas encontraban.

Antes de su muerte, de Winghe le entregó toda la documentación que habían conseguido reunir a un estudiante maltés: Antonio Bosio. Junto con esa información, Bosio recogió de los itinerarios, de las descripciones de los Santos Padres y de las informaciones locales toda la documentación existente sobre las catacumbas. De este modo, junto con Pomponio Ugonio e impulsado por San Felipe Neri, de quien era discípulo, en 1593 comenzará la investigación sistemática de las catacumbas de Roma. El resultado de sus treinta años de trabajo fue su famosa obra Roma Sotterranea, editada de manera póstuma por Juan Severo de San Severino hacia 1632.

Roma Sotterranea supone la expresión de los primeros trabajos científicos sobre arqueología cristiana realizados en Roma, pero en realidad esta obra es mucho más que el trabajo de un sólo hombre. En ella se condensan los esfuerzos de todas aquellas personas que durante siglos trabajaron en el campo de la arqueología y que con sus aportaciones hicieron posible el trabajo de Bosio y en definitiva, el nacimiento de la arqueología cristiana.

dueño de una de las colecciones privadas más famosas de España, algunas de cuyas piezas escultóricas se conservan en la actualidad en el Museo del Prado. 


\section{BIBLIOGRAFÍA}

CASTRO, A. (1987) Los circulos del poder. Aparta Vaticano. Madrid.

FERRUA, A. (1938) "Le tre Rome sotterranee". Civiltà Cattolica III,. 399-412.

FLICHE y MARTÍN (1978) Historia de la Iglesia.

T.XX. Valencia.

FREND, W. H. (1997) The Archaeology of Early Christianity. A History. Londres.

GARCÍA VILLOSLADA, R. (Dir.) (1980) Historia de la Iglesia en España. T. III- $1^{\circ}$. Madrid.

GARCÍA VILLOSLADA, R. (Dir.) (1980) Historia de la Iglesia en España. T. II-2 ${ }^{\circ}$ Madrid.
GUTIERREZ, G. (1951) Españoles en Trento. Valladolid.

LLORCA, B.; $\mathrm{G}^{\mathrm{a}}$ VILLOSLADA, R. $\mathrm{y}$ MONTALBÁN, F. (1967) Historia de la Iglesia Católica. T.III. Madrid.

MERIOL, T. (1986) San Felipe Neri, apóstol de Roma (1515-1595). Bilbao.

QUINTÍN; MARÍN, T. y VIVES, J. (1972) Diccionario de Historia Eclesiástica de España. Madrid.

TÜCHLE, H. (1966) Nueva Historia de la Iglesia. T. III. Madrid.

VON RANKE, L. (1981) Historia de los papas en la época moderna. Méjico. 